IZA DP No. 7403

Is the Contracting-Out of Intensive Placement Services More Effective than Provision by the PES?

Evidence from a Randomized Field Experiment

Gerhard Krug

Gesine Stephan

May 2013 


\title{
Is the Contracting-Out of Intensive Placement Services More Effective than Provision by the PES? Evidence from a Randomized Field Experiment
}

\author{
Gerhard Krug \\ $I A B$, University of Erlangen-Nuremberg \\ Gesine Stephan \\ $I A B$, University of Erlangen-Nuremberg \\ and IZA
}

Discussion Paper No. 7403

May 2013

IZA

P.O. Box 7240

53072 Bonn

Germany

Phone: +49-228-3894-0

Fax: +49-228-3894-180

E-mail: iza@iza.org

\begin{abstract}
Any opinions expressed here are those of the author(s) and not those of IZA. Research published in this series may include views on policy, but the institute itself takes no institutional policy positions. The IZA research network is committed to the IZA Guiding Principles of Research Integrity.

The Institute for the Study of Labor (IZA) in Bonn is a local and virtual international research center and a place of communication between science, politics and business. IZA is an independent nonprofit organization supported by Deutsche Post Foundation. The center is associated with the University of Bonn and offers a stimulating research environment through its international network, workshops and conferences, data service, project support, research visits and doctoral program. IZA engages in (i) original and internationally competitive research in all fields of labor economics, (ii) development of policy concepts, and (iii) dissemination of research results and concepts to the interested public.
\end{abstract}

IZA Discussion Papers often represent preliminary work and are circulated to encourage discussion. Citation of such a paper should account for its provisional character. A revised version may be available directly from the author. 


\section{ABSTRACT}

\section{Is the Contracting-Out of Intensive Placement Services More Effective than Provision by the PES? Evidence from a Randomized Field Experiment ${ }^{*}$}

There is a longstanding debate on the advantages of quasi-markets for placement services compared to their public deliverance. During 2009, the German Public Employment Service (PES) implemented a randomized field experiment to investigate if intensive services for hard-to-place unemployed individuals can be provided more effectively by such private providers or by PES in-house teams. Unemployed persons were assigned to intensive services for a period of eight months. This paper presents the first results of this experiment; the observation period covers 18 months after assignment. Initial in-house provision reduces accumulated days in unemployment by one to two months. Approximately two thirds of this effect is attributable to labor market withdrawals. The effect on the share of individuals in a given labor market status (unemployed, employed, and withdrawn) occurs mainly during the program period of eight months and disappears by the end of the observation period. We conclude that in a particular environment, the public provision of placement services can be as least as effective as contracting-out - a simple comparison of effectiveness might, however, be misleading.

JEL Classification: J68, J64, J65

Keywords: randomized field experiment, contracting-out, intensive placement services

Corresponding author:

Gesine Stephan

Institute for Employment Research (IAB)

Regensburger Str. 104

90478 Nuremberg

Germany

E-mail: gesine.stephan@iab.de

\footnotetext{
${ }^{*}$ We thank the Pinguin-project team of the PES for its cooperation, the CF15 unit of the German Public Employment Service - in particular Michael Irskens and Thomas Büttner - for providing data from the TrEffeR data base and the ITM unit of the Institute for Employment Research - in particular Ali Athmani - for supporting the implementation and maintenance of the EMu database as well as providing data from additional data sources. Furthermore, we are grateful for the helpful comments received after seminar presentations at the Universities of Mannheim, Linz and Hamburg, the 2011 IZA/SOLE Transatlantic Meeting of Labor Economists, the 2011 Annual Conference of the "Verein für Socialpolitik", the 2012 Annual Conference of the Royal Economic Society, the 2012 Annual Meeting of the Research Committee on Population Economics of the "Verein für Socialpolitik", and the 2012 IAB-Conference on Field Experiments in Policy Evaluation. An earlier version of the paper was published as LASER discussion papers 51.
} 
"What kinds of goods and services should be provided by government employees as opposed to private firms?" is the opening question of an overview by Andrev Shleifer (1998: 133) at the end of the nineties. He concludes that "Private ownership should generally be preferred to public ownership when the incentives to innovate and to contain costs must be strong." (1998: 147) While not explicitly discussed by Shleifer, a particularly interesting case from a labor economics point of view is certainly the provision of placement services or job brokerage. In most European welfare states, placement services have typically been provided by public employment services (PES). The state provision of such services has, however, been increasingly criticized for its presumed lack of efficiency. State agencies delivering placement services are not subject to pressure from a competitive market and are therefore presumed to lack incentives to control costs, provide quality service and respond to the needs of consumers (Grout/Stevens 2003). Contracting-out to private providers has been proposed as a solution to this problem; it involves the creation of quasi-markets in which several potential providers compete. However, potential agency problems that arise when services are contracted out have to be considered carefully (Behaghel et al. 2012, Courty/Marschke 2004, Heckman et al. 2002, Koning/Heinrich 2010).

Our contribution to the debate is based on a field experiment that was designed to obtain deeper insights into the effectiveness of public versus private provision of intensive placement services for hard-to-place unemployed persons. We investigate the medium-run labor market results of two programs that aimed to improve the employability of the unemployed, diminish and overcome their placement deficits, place them into regular jobs, and stabilize the newly established employment relationships. One program is based on the idea of contracting-out, whereas the other one is based on the in-house production of PES. Our analysis draws on data from two local German labor market agencies where randomized field experiments were conducted during 2009 and 2010. A distinguishing feature of our study is the very high compliance rate of assigned persons as participation was (mostly) mandatory.

Contrary to what could have been expected, our results show that at least in the short run, inhouse provision can in fact be more effective than contracting out and results in fewer accumulated days in unemployment. One third of the positive effect is attributed to exits into employment, and the other two thirds are attributed to other withdrawals from registered unemployment. Furthermore, we find that assignment to in-house services reduced the share of unemployed persons mainly during the program period of eight months, whereas the effect diminishes thereafter. Eighteen months after assignment, the re-employment rates of the hard-to-place remain low in both the treatment and control groups. All in all, we conclude that neither regime provided lasting help for this challenging group of unemployed individuals. 
Two strands of the literature are particularly relevant to our research question. The first relates to the effectiveness of intensive placement services in general; the second compares contractedout and in-house placement services.

As far as we can see, most empirical evidence points toward the general effectiveness of intensive placement services for the general unemployed population. Hofmann et al. (2012) analyze a non-randomized German experiment in which additional caseworkers were hired by fourteen public employment offices to lower caseloads and improve the quality of placement services for unemployment insurance recipients. They show that with lower caseloads, agencies of the PES could intensify counseling and monitoring efforts as well as contacts with local firms. Performing a two-step matching on the regional and individual level, the authors find shorter durations of unemployment for individuals seeking assistance from public employment offices with lower caseloads. Using a difference-in-differences matching strategy, Hainmueller et al. (2011) conclude for the same pilot project that caseworkers with lower caseloads were able to acquire more vacancies and imposed more sanctions than their counterparts with higher caseloads, leading to shorter unemployment durations and higher re-employment rates. Hägglund (2009) presents randomized experimental evidence from Sweden on the effects of intensive placement efforts (i.e., job search assistance and monitoring, high contact frequency) compared to standard services on the subsequent employment and earnings of Swedish participants. Due to low caseloads, he finds mainly insignificant effects. Nevertheless, intensive services seem to reduce unemployment among the treated compared to standard services. Pedersen et al. (2012) analyze four randomized social experiments that were conducted in Denmark in 2008. The experiments consisted of different combinations of early and intensive treatment in terms of meetings and active labor market programs. The authors find that in particular individual meetings between newly unemployed workers and case workers can increase employment rates over the next two years by up to five weeks.

Empirical studies comparing contracting-out and in-house production of placement services are rather scarce. One of the main difficulties is that most countries that implement contracting-out systems do so for the entire unemployed population (e.g., Australia), for all unemployed individuals with certain characteristics (e.g., the hard-to-place in the Netherlands) or for all unemployed individuals in a certain region (e.g., the thirteen regional employment zones in Great Britain). This situation makes it difficult to control for temporal or regional differences in labor market conditions, which also influence the effectiveness of re-employment services.

We are aware of two randomized experiments in this area. Perhaps the closest to our study is a randomized experiment that was conducted in France during the years 2007 and 2008 and evaluated by Behaghel et al. (2012). Job seekers were assigned to either a private or public program offering intensive counseling or a control group receiving standard services. Private providers as 
well as unemployed persons were allowed to refuse the assignment; thus, the compliance rates of those assigned to intensive counseling amounted to approximately 50 percent in both treatment groups. Outcomes were observed for up to one year after assignment took place. The authors find a positive impact of such intensive job search assistance in France on exit rates to employment (15 to 35 percent higher exit rates to employment during the six months after assignment), which is considerably higher for the public than for the private program. The authors presume that the underlying contract structure with private providers did not overcome agency problems: The payment structure provided incentives to enroll as many job-seekers as possible into the program and serve them with minimal effort because 30 percent of remuneration was paid up-front. Bennmarker et al. (2013) focus on unemployed under the age of 25, immigrants and disabled persons in Sweden. The authors utilize random assignment as an instrumental variable for private job placement, because compliance with assignments was voluntary and amounted to 28 percent. They find no effects on the probability of employment among all three groups combined, although there is evidence for positive effects on migrants and negative effects on young unemployed individuals. These effects disappear over time, indicating that no long-term effects were realized.

For unemployment insurance recipients in Germany, the few existing econometric evaluation studies use propensity score matching to find treatment and comparison groups composed of similar individuals who received contracted-out and placement services by the PES, respectively. The studies indicate that the placement services of private providers might at best be as effective as those produced in-house. Winterhager (2006a, 2006b, 2008) uses propensity score matching and analyzes assignments taking place during 2004. He finds significant small and negative short-term effects of private placement services on the employment prospects of individuals assigned to a private placement agency. Winterhager attributes these results to deficits in contract management at the time, when low prices were coupled with low quality. Similarly, WZB/infas (2006) find no effects on employment four months after assignment among unemployed individuals assigned to private providers in Germany during 2003 and 2005. For recipients of means-tested benefits (unemployment benefit II) who were assigned to a private provider during 2005, the results of Bernhard/Wolff (2008) suggest that such an assignment is generally ineffective and is even counterproductive in some subgroups. Nonetheless, for selected groups of job-seekers who are rather hard to place, the authors find the assignment to be effective.

The remainder of our paper is organized as follows. Section 2 presents some theoretical considerations and explains contracting-out practices in Germany. Section 3 introduces the randomized field experiment implemented by the German PES as well as the employed data and methods. Section 4 contains our empirical results, and Section 5 concludes. 


\subsection{Theoretical background}

The primary advantage of contracted-out placement services is often seen in a higher efficiency of private service providers due to competitive market mechanisms. In this regard, it seems important to distinguish contracting-out from privatization. Whereas the latter includes the transfer of physical assets from public to private ownership, contracting-out means that a set of economic activities that was previously not open to competition is now open for it (Domberger/Jensen 1997). Competition through contracting-out usually implies so-called ex-ante competition, which is competition for a market rather than competition in a market. This market is denoted as a "quasi-market" (Bartlett/Le Grand 1993) because it has some important differences from a conventional market: Whereas several (for-profit or non-profit) service providers are competing with each other on the supply side, on the demand side, consumer purchasing power is centralized within a single state purchasing agency (a variant that we do not discuss further is consumer purchasing power in the form of vouchers). In quasi-markets, competition is achieved through contract specifications and a bidding process that is similar to an auction. The lowestprice bidder wins the right to supply for a specified period of time (Struyven/Steurs 2004). A state agency specifies the tasks to be performed by private providers within contracts. Therefore, the state maintains a certain amount of control over the activities of private providers, which would not be the case if placement services were privatized (Domberger/Jensen 1997).

Compared to monopolistic state providers, a given contracting-out scheme will achieve its goal of enhancing efficiency only insofar as such a competitive quasi-market is successfully established (Bartlett/Le Grand 1993). A prerequisite for this establishment is that there should be no barriers to market entry and that new providers must have the opportunity to enter the market. Likewise, providers should run the risk of making losses and must consequently face the danger of exiting the market. Additionally, prices in quasi-markets should reflect the interaction of supply and demand, which is usually achieved through negotiations between the state purchasing agency and potential service providers.

However, because the implementation of a quasi-market is not trivial, contracting-out schemes have not always been able to deliver on their promises. One major reason for this inability is made explicit by arguments based on transaction-cost theory (Boardman/Hewitt 2004, Williamson 1985). From this perspective, quasi-markets or contracting-out are not necessarily always the most efficient way to provide placement services. Assume bounded rationality, high uncertainty about the future state of the labor market, and high asset specificity. First, because employment services were exclusively provided by public services for a long time, the problem of 
a low level of ex ante competitiveness may arise: The number of potential providers can be rather small. Second, there might be certain investments that are specific to the transaction at hand (asset specificity). For instance, specialized software might be needed to deliver placement services, caseworkers must have specific skills to provide particular placement services, or relationships to potential employers have to be built and fostered. Such transaction-specific investments make it costly for providers to switch purchasers and vice versa. Additionally, writing and monitoring the contracts specifying the tasks and remuneration of private providers requires specific skills that have to be acquired or bought by the respective government agency. Given uncertainty with regard to the development of the labor market, contracts that pay providers on the basis of results might require a risk premium. Because of such transaction costs, in some cases, it might be more efficient to turn to in-house production than to contract out placement services.

The design of the remuneration scheme can also be regarded as an agency problem. Because contracting-out relies on incentive-induced behavior, serious consequences can result if incentives are not well-designed (Bruttel 2005a). The first problem relates to the chosen payment structure. Finn (2007) distinguishes between three pure types of contracts: Pure pay-forperformance contracts, cost-imbursement contracts, and fixed-price contracts. In practice, hybrid contracts are often sought to balance incentives, viability and the delivery of particular services. Behaghel et al. (2012) develop a model of heterogeneous job seekers who differ in their initial job offer probabilities and the impact of counseling on their probabilities of finding jobs. Both are unobserved by the state agency providing unemployment benefits. Private providers are offered contracts consisting of an up-front fixed payment and a job-finding premium. Assuming that impact heterogeneity is larger than initial heterogeneity, the authors derive the optimal contract structure. A major factor is that the size of the fixed payment component should be negatively related to the costs of improving labor market prospects for the private provider, whereas the performance payment component should be positively related with these costs. The incentive for "creaming" - accepting only individuals that have comparatively good labor market prospects - increases with the weight of the performance payment component. In contrast, the incentive to "park" hard-to-place individuals increases with the importance of the up-front payment component and if integration proves to be too costly. The second problem is how the performance of private providers is monitored (Bruttel 2005a). One concern is that whereas the rewards for providers should mirror the net impact of their treatment, information on provider effectiveness is generally not available, and gross integration rates are taken as a proxy for net impact. 


\subsection{Institutional context}

Most OECD countries underwent comprehensive reforms to their welfare systems in the late 1990s. An important component of these reforms was the introduction of market mechanisms in the delivery of placement services. In Germany, the PES traditionally held a monopoly in the delivery of placement services (Konle-Seidl 2005). Therefore, an important precondition for contracting-out was the removal of barriers to market entry for private placement service providers. The step-by-step introduction of market mechanisms to the German placement service system can be characterized as "a pragmatic approach on a trial-and-error basis rather than as a well-designed contract management approach" (Konle-Seidl 2005: 190). In general, private job placement services have been admitted since 1994. Since 1998, a PES program allowed for parts of placement services - such as profiling and case management - to be outsourced to private providers. However, until 2002, private placement services needed to obtain a license from the PES. The abolition of licenses was meant to increase competition between private and public providers. In 2002, the scope of contracting-out was widened from parts to the complete placement service: After six months of unsuccessful placement efforts by the public employment agency, jobseekers could demand to be transferred to a private provider. The goal was mainly to reduce the caseloads of public employment services by delegating (but not yet contracting-out) placement services to private providers. The selection of providers and assignment of the unemployed still occurred on a discretionary basis while the PES remained fully responsible for successful placement activities even if they had been outsourced. Finally, in 2003, a tendering process was introduced, and contracts containing performance-incentives were concluded, thereby introducing a system of contracting-out.

The privatization of placement services, however, was only one aspect of the German reforms. Indeed, an extensive effort was and is still focused on increasing the efficiency of the public employment services system. Reforms of public employment services based on the concepts of New Public Management have replaced bureaucratic input-based administrative structures with output-oriented performance management (Sol/Westerveld 2005). In 1999, the German PES implemented a performance management system based on management by objectives (Mosley et al. 2001). Management by objectives is a performance management system driven by quantified targets. It consists of target setting, decentralized operations, and the continuous monitoring of results (Mosley et al. 2001: 3). In Germany, targets are negotiated among the public employment agency headquarters, regional headquarters and operating units. At the same time, policy discretion was delegated to the regional level. Local offices are now more flexible in allocating resources according to their discretion and deciding the local policy mix but are held accountable for the success or failure of their policies. Objectives are instrumented through a 
number of performance indicators that are provided on a monthly basis. At the executive level, wage premiums are awarded depending on the degree to which these objectives are fulfilled (Kaltenborn et al. 2010). Thus, incentives for effective and efficient services are present even in the absence of external competition.

As an integral part of placement services in Germany, caseworkers conduct a soft profiling of individuals entering into unemployment to identify their service needs. Individuals classified as "hard-to-place" are expected to have difficulties with regard to their abilities as well as their motivation to return to the labor market and are therefore supposed to benefit from intensive placement services. In our empirical analysis, we are concerned with a specific contracting-out scheme that came into existence in 2008 and was targeted toward individuals classified as hardto-place. During the considered time period, caseworkers were advised, after four months of unemployment, to assign hard-to-place unemployed individuals to a private provider where they would receive intensive placement services. Unemployed persons remaining in the PES system continued to receive regular employment services. Whether unemployed persons were actually assigned was at the discretion of individual caseworkers. This practice is formally considered to be a labor market program, and its acronym is "Ganzil". In 2009, more than 220,000 unemployed individuals were assigned into this program.

To avoid creaming, private providers could not refuse to enroll unemployed persons assigned to them. Assigned unemployed persons themselves could reject enrollment with a private provider only for good reasons; non-compliance could result in a period of being cut off from benefits. Contracts contained a clause obligating private providers to guarantee a minimum frequency of contact. During the time period under investigation, assigned unemployed persons had a contact frequency of at least every two weeks. Other than these restrictions, private providers were free to choose what types of placement services they wanted to provide and how. Usually, Ganzilcontracts for private providers encompass a period of two years and are negotiated by the responsible state agency and the respective provider.

A multi-tier payment structure is supposed to create incentives for entering and staying in the market in the presence of fixed costs while at the same time creating incentives for the efficient provision of placement services. Payment for private providers consists of a fixed payment component per unemployed person (usually ranging from 700 to 990 euro) and two performance payment components (usually ranging from 150 to 1,500 euro each). Out of the fixed components, participants have to be reimbursed for commuting costs and costs arising from

Ganzil is short for „Ganzheitliche Integrationsleistungen für Arbeitslose mit Aktivierungs- und Unterstützungsbedarf sowie multiplen Vermittlungshemmnissen und geringen Integrationschancen". 
applications. One part of the performance payment is due after an unemployed person has been in a regular job for three months, and the other part is due after six months. Instead of performance payment, a risk component might be awarded if previous participants had not been registered as unemployed for at least 4 months. Furthermore, contracts specify a minimum successful re-employment rate (usually between 20 and 30 percent); if a provider fails to reach this rate, a malus payment is imposed per failed re-integration.

To summarize our discussion of the theoretical and institutional background, the comparative advantage of quasi-markets depends, on the one hand, on the quality of its implementation within a given institutional framework, i.e., whether a quasi-market has been successfully implemented and how contracts are designed. On the other hand, a crucial factor is the quality of services produced in-house by public placement services. In light of the recent decentralization of public placement services and the specifics of the in-house placement service scheme, the dichotomy of equating private programs with flexibility and public programs with bureaucratic inflexibility no longer seems to be applicable. This situation makes the issue of effectiveness and efficiency an empirical question.

The field experiment, data, and empirical approach

\subsection{The randomized field experiment}

After several non-experimental evaluations indicated mostly no difference in the effectiveness of services provided by public and private placement services, in 2008, the German PES started the "Pinguin" 2 pilot project. The pilot was intended to test whether intensive placement services for hard-to-place unemployed individuals could be delivered as effectively and efficiently inhouse as standard placement procedures at the time involving contracting-out on a discretionary basis.

Our empirical analysis draws on an important part of the pilot that began with two agencies in April and June of 2009: In these agencies, hard-to-place unemployed individuals were randomly

2 Pinguin is short for „Projekt Interne ganzheitliche Unterstützung zur Integration im SGB III“. The first wave of the project was implemented in three local employment agencies where all target group members were assigned to in-house services. In an internal review, the PES compared the aggregate labor market results of participating regional agencies with those of synthetic agencies with similar labor market characteristics. It was noted, however, that this comparison lacked internal validity because even similar labor markets will still contain different unobserved features. Thus, the second wave of the pilot project was implemented in three additional employment agencies. This paper analyzes two of these; in the third agency, however, assignment to a private provider was not mandatory. Because of its very different design, this agency will be subject to a different investigation. 
assigned to two groups. The control group received contracted-out placement services, whereas the treatment group was assigned to a special team within the local employment agency. Both types of intensive placement services were delivered for a period of approximately eight months. Then, individuals who were still registered as unemployed returned to the local employment agency to receive standard public employment services (i.e., not intensive services as before).

Internal teams differ from other teams in the PES because of their comparatively low intended caseload of 1:40. Realized caseloads were mostly even lower, in particular during the first months of the project (see Figure A.1. in the Appendix). The teams had more freedom in allocating working time and fewer restrictions in their placement activities than other caseworkers. Furthermore, they had discretion in utilizing a fixed budget of 576 euro per participant for active labor market programs (such as short training programs or longer-term additional training). The intention was to create incentives for the efficient use of resources. Originally, participation in the project was restricted to individuals registered as unemployed (receiving unemployment benefits or searching without receiving benefits) who had not registered with the public employment service during the previous six months. Unemployment benefit recipients should have a benefit entitlement length of at least three months. Because inflow into the project was lower than the PES had expected, however, several individuals from the stock of unemployed were also randomly assigned.

The design of the experiment in both agencies differed only with regard to the timing of the intensive placement service. In Agency 1 (located in East Germany), random assignment took place immediately after registering as unemployed, whereas in Agency 2 (located in West Germany), random assignment took place only four months after registering as unemployed.

Random assignment was based on a computer program, "EMu", which was developed by the PES for evaluation purposes. Caseworkers were instructed to call the program after an unemployed person had been categorized as hard-to-place. This instruction is important for the credibility of the experiment: Even if we have no reason to believe that the experiment had an impact on the profiling decisions of caseworkers, individuals classified as hard-to-place would have the same probability of being assigned to internal or external placement services in any case.

After randomization, caseworkers were instructed to immediately assign unemployed persons to the private placement agency or the internal team within the agency. Although the transition into in-house services occurred without friction, there was usually a time interval between randomization and the first appointment with the private provider of intensive placement services.

3 EMu is short for "Elektronischer Muenzwurf" (i.e., "throwing an electronic coin"). 
Several assigned control group members de-registered from unemployment during this period. Furthermore, approximately 20 percent of the control group did not participate in the program, although they were unemployed for quite some time. We will address both of these aspects in Section 4.3.

\subsection{Data, sample, and outcome variables}

The results from the randomization computer program $(\mathrm{EMu})$ were stored in a central database. We use the EMu database to identify members of the control and treatment groups. We match administrative information from the so called TrEffeR database (Stephan et al. 2006), which was constructed for monitoring purposes by the PES. It merges data flows from the computerbased operating systems of the Public Employment Service on periods of registered job search, registered unemployment, participation in labor market programs and employment that is subject to social security contributions. The version we use relies on information obtained from administrative systems on February 28, 2012. We utilize data until the end of August 2011 because employment information in particular is partially delayed. With these data, we merge additional information on employment features ( $\mathrm{BeH}$ database), cut-off periods from benefits (LeHS database), and features of the contracted-out program (MTH-P46 database) from process-generated research data files provided by IAB.

The sample analyzed in this paper covers entries into the project after April 17, 2009, when the randomization tool was implemented, until the end of February 2010. We exclude all persons who entered unemployment before January 1, 2009 as being "stock unemployed" and all individuals who would have been 64 years of age or older at the end of this observation period (regular retirement takes place at the age of 65). The remaining sample covers 816 observations in Agency 1 and 532 observations in Agency 2. We observe these individuals for a period of eighteen months.

The effectiveness of placement services can be measured in various ways. We distinguish three main outcome variables that capture different aspects of successful placements. The first outcome variable is accumulated days of registered unemployment during the eighteen months after assignment. This outcome variable is not only important to individual job seekers but also of particular importance to public employment agencies because every registered unemployed person is a (costly) consumer of placement services. The second outcome variable is accumulated days in regular employment during the eighteen months after assignment (covered by social security, thus excluding marginal employment). The third outcome variable is accumulated days in which an individual was not registered as unemployed or employed, which in most cases is a result of withdrawal from the labor market. Additionally, a graphical representation of the 
shares of persons in these labor market positions at a given point in time, specifically at the end of our observation period, is presented. These shares do not necessarily add up to one because individuals might be employed part-time (up to fifteen hours/week) and registered as unemployed at the same time.

In the case of those who found employment, job quality is also of interest. To obtain an impression of job quality, we analyze accumulated earnings during this time period. Because, however, this outcome variable is highly correlated with accumulated days in employment, we furthermore investigate daily wage rates for all workers covered by social security (including part-time workers) as well as restricted to the group of full-time workers.

\subsection{Empirical approach}

For a formal representation of the experiment, assume that $Z_{i}=0$ indicates that individual $i$ is randomly assigned to the contracting-out scheme, whereas $Z_{i}=1$ indicates immediate assignment to the internal teams. Accordingly, $\mathrm{Y}_{0}$ and $\mathrm{Y}_{1}$ are the labor market results of individuals receiving standard treatment or new services. Because of random assignment, $E\left[Y_{i}(0) \mid Z=1\right]-$ $E\left[Y_{i}(0) \mid Z=0\right]$ should equal zero. Thus the difference $E\left[Y_{i} \mid Z=1\right]-E\left[Y_{i} \mid Z=0\right]$ measures the causal effect of $Z$ on $Y$ (see for, instance, Duflo et al. 2008). This effect does not, however, mirror the effect of in-house production versus contracting-out because $Z_{i}=0$ does not equal the actual receipt of services of a private placement provider. As we will see, compliance reached 100 percent for in-house services, whereas just under 80 percent of those assigned to a private provider actually began the program. However, $\mathrm{Z}$ at least has a strong influence on the type of services received; thus, the difference represents the effects of in-house treatment versus likely assignment to a private provider.

In the situation described above, assignment cannot be used as an instrumental variable for actual participation: For clarification, assume that $T_{i}=\theta_{0}$ denotes that an individual $\mathrm{i}$ was assigned but did not go to a private provider (this individual might either have dropped out of registered unemployment or received standard services instead of intensive services). $T_{i}=\theta_{1}$ denotes that individual $i$ went to a private provider, whereas $T_{i}=\theta_{2}$ implies that individual $i$ went to the internal team (where we observe perfect compliance). Estimating $Y_{i}=\beta_{0}+\beta_{1} T_{i}$, the selection into $T_{i}=\theta_{0}$ and $T_{i}=\theta_{1}$ is most likely not exogenous. However, although $\mathrm{Z}$ is correlated with $\mathrm{T}$ and uncorrelated with $Y, Z$ provides no information on the choice between $T_{i}=\theta_{0}$ and $T_{i}=\theta_{1}$.

Thus, to analyze (un-)employment outcomes as well as earnings, we start with simple ordinary least squares (OLS) estimates that encompass only a treatment indicator as an explanatory variable. In subsequent steps, the OLS estimate will be enriched by further explanatory variables. 
Even in randomized experiments, some covariate imbalance can remain, especially at the beginning of a project, when the number of participants is still rather low. Thus, we conduct an additional statistical matching analysis that provides weights for the regression analysis. To test for similarity between those receiving standard services versus those receiving intensive in-house services, the mean standardized bias ${ }^{4}$ (MSB) (Rosenbaum/Rubin 1983) is computed across a number of individual characteristics, which are variables describing employment history and calendar month of assignment. In consequence, we perform an additional radius matching ${ }^{5}$ (Dehejia/Wahba 2002) with a caliper of 0.05 , which estimates the counterfactual by matching participants to a weighted average of all persons within the radius of the respective propensity score. For matching, we consider only individuals who are in common support. For these individuals, the data indicate a positive probability of participating in standard as well as intensive in-house services.

Furthermore, to estimate the effects of an assignment on daily wage rates, we must take into account that only the wages of employed persons are observed. Without imposing ad hoc distributional assumptions, only bounds on treatment effects can be computed. Horowitz/Manski (2010) suggested "worst case bounds", imputing outcomes from a bounded interval to nonemployed persons. In our case, however, the resulting bounds are extremely wide and uninformative.

Thus, following the approach suggested by Blanco et al. (2013; see also Lee 2009 and Zhang et al. 2008), we restrict our analysis on the strata of individuals who can be supposed to be employed regardless of treatment assignment; we will denote them as "always employed persons". First, we invoke an individual-level monotonicity assumption (based on the fact that we find no negative employment effects of assignment to internal services): We assume that each individual who is employed if assigned to a private provider will also be employed if assigned to internal services. To obtain the upper (lower) bound, we trim the distribution of observed outcomes for the treatment group from below (above) until the remaining share of treated persons equals the share of employed persons in the control group. Treatment effect bounds are than obtained by computing differences across the mean of the trimmed distribution for the treatment group and the mean for the control group. Second, we tighten the bounds further by adding a weak

4 The standardized bias of a covariate is defined as the difference of means in the treated and matched comparison sample divided by the square root of the average sample variance. For comparison using statistical matching techniques, Caliendo/Hujer (2006) summarize that most studies find a MSB of 3 or 5 percent as acceptable.

5 Radius matching reduces the variance of estimated treatment effects by using information from several potential comparison persons to construct the counterfactual for each participant, whereas setting a caliper - a maximum distance of propensity scores between treated and comparison persons - avoids the risk of bad matches (Caliendo/Kopeinig 2008). The criterion for the caliper choice was the size of the mean standardized bias after matching. 
monotonicity assumption of mean potential outcomes across strata. The underlying idea is that the strata of "always employed persons" comprises more able individuals than the strata of persons who are only employed when receiving internal services. In this case, the upper bound on treatment effects is obtained (as before) by trimming the distribution of observed outcomes for the treatment group from below (as has been described above), whereas the lower bound is computed using the mean observed outcomes in the treatment and control groups. In both cases, standard errors for the bounds are obtained by bootstrapping (1000 replications on a 90 percent sample).

\section{$4 \quad$ Empirical analysis}

\subsection{Individual characteristics and further program participation}

Table 1 displays the distribution of characteristics for both groups under consideration. We find very few significant differences across both randomly assigned groups. The mean standardized bias between both groups takes values of 7.1 and 6.7, respectively. Figure A.2 in the Appendix shows the distribution of the propensity scores and the estimated probabilities of being assigned to treatment, which differ partly in Agency 1 . Thus, we will present some additional results after statistical matching took place. As seen from the last row in Table 1, balancing considerably improves through matching (after matching, we do not find any significant differences between the means of individual characteristics across both groups).

[Table 1 about here]

Regarding individual characteristics, the two agencies are obviously different, reflecting general differences between East and West Germany. In the Eastern German Agency 1, the share of hard-to-place individuals who do not receive unemployment benefits amounts to approximately 30 percent, whereas it is only approximately 10 percent in the Western German Agency 2. Within the Eastern German agency, women constitute more than 60 percent of hard-to-place unemployment entries, which is 10 percentage points more than in the Western German agency. The share of individuals looking for part-time work, the share of foreign nationals and the share of individuals without a secondary education or vocational training is much lower in the Eastern German agency than in the Western German agency. In both agencies, individuals between the ages of 50 and 59 constitute approximately 40 to 50 percent of project participants.

Table 2 presents the share of individuals participating in active labor market programs. The share of individuals in the control group who are actually receiving private placement services (Ganzil) amounts to nearly 80 percent of the control group. Thus, not all control group members 
actually receive private placement services, even if they were meant to. We will return to this point in Section 4.3.

\subsection{Causal effects of internal services}

[Figure 1 about here]

[Table 3 about here]

Figure 1 displays the temporal development of the causal effects of intensive in-house services on accumulated days of unemployment, regular employment and in other positions (i.e., labor market withdrawal). For both agencies, intensive in-house services significantly diminished days spent in unemployment. Table 3 presents estimates of cumulative effects at the end of our observation period of 540 days. The constant indicates mean days in unemployment for unemployed persons who were assigned to contracted-out services, whereas the estimated coefficient for intensive in-house services shows the differential effect of internal services. Panel I of Table 3 confirms that the studied individuals were, in fact, hard to place: During the observation period of eighteen months, control group members spent an average of approximately twelve months in unemployment and were employed for about two months.

Individuals assigned to in-house services spent more than one month (Agency 2) or two months (Agency 1) less in unemployment. However, internal services produced a reduction in accumulated days of unemployment partly by placing individuals in employment and partly by producing labor market withdrawals (Figure 1 and Table 3). In fact, only one third of the effect of inhouse services is due to more days in employment, whereas two thirds is due to more days in which individuals who were subjected to public placement services are withdrawn. The latter effects are, however, significant only for Agency 1. If weights from a matching analysis are applied (Panel II of Table 3), the estimated effects are slightly smaller in size but the signs of the effects do not change.

[Figure 2 about here]

Furthermore, the success of in-house services seems to have mainly occurred in the short run and during the program duration of eight months. Figure 2 presents the share of individuals in a given labor market status during several points in time until the end of our observation period. For instance, 180 days after assignment to Agency 1, the share in unemployment was 20 percent lower for individuals subjected to in-house services. However, over time the difference becomes smaller; 540 days after assignment, it is no longer significant. A similar development can be observed for Agency 2, where the difference becomes statistically insignificant after slightly more than 360 days. The difference in shares in employment, which is not very high to begin 
with, also becomes smaller and insignificant over time. Similarly, effects on shares in labor market withdrawal become small and statistically insignificant over time.

All in all, individuals in in-house services seem to have returned to unemployment more often some time after becoming employed or after they were motivated to deregister. It seems that inhouse services were effective during the duration of the program, but program effects were not sustainable. A potential reason for employed persons to return to unemployment might be that the jobs they were placed in by in-house services had comparatively lower wages. This will be investigated in the next step.

\section{[Table 4 and 5 about here]}

Table 4 contains results on accumulated earnings during our observation period: No significant differences can be found between both groups. To analyze daily wage rates, we follow the approach suggested by Blanco et al. (2013) and present bounds on the effects for "always employed" persons (see Section 3.3 for a description of the method). For the first job after assignment until the end of 2010, Table 5 displays differences between the jobs taken by individuals subjected to in-house and contracted-out placement services. We present results for all persons who take jobs and in addition - because further information on working times is missing - results only for the group of persons who are working full-time. As mentioned in Section 3.3, due to selection issues, we can present only bounds for the size of the effects restricted to the group of "always employed" persons. For Agency 2, these bounds do, in fact, reduce to point estimators because the share of employed persons is essentially the same in the treatment and control groups. All bounded intervals span zero at $\alpha=0.95$ : For instance, in Agency 1, differences in daily wages for all workers covered by social security are bounded between -10 and 0 euro under an individual-level monotonicity assumption (trimming the additional share of observations with wages in this group from above and from below, respectively). Whereas the lower bound is significantly negative, the upper bound is not significantly different from zero. Nonetheless, the data provide some tentative evidence that there is a trade-off between a quick reintegration and wages and that the temporarily higher re-integration results of in-house services might have resulted from placing individuals in jobs with lower wages.

\subsection{Differences across agencies}

We will now turn to the question of why results may differ between both agencies. There are several potential reasons that internal teams in Agency 1 have performed better than the contracted-out services, whereas the difference was much smaller in Agency 2. Caseloads per caseworker were slightly lower during 2010 in Agency 1 than in Agency 2 (Figure A.1). Random assignment took place approximately four months earlier in Agency 1; thus, early interven- 
tions might be more successful. Furthermore, the internal team of Agency 1 could have exerted more effort or developed more successful strategies than the team of Agency 2, whereas the opposite might have been true for the private providers in both regions. Finally, the labor market conditions and characteristics of participants in Agency 1 might simply have been more suited to the types of services provided by the project.

Although we cannot test for all potential reasons, an interesting point is that the share of nonbenefit recipients was much higher in Agency 1 than in Agency 2, which is most likely related to the fact that Agency 1 is located in East Germany, whereas Agency 2 is in West Germany. Non-benefit recipients are most likely more willing to de-register because they do not receive financial benefits from unemployment anyway. Incentives to push non-benefit recipients out of registered unemployment are prevalent for both private and public placement services: Private providers of placement services receive performance payment components for those entering (stable) employment but also a risk component for individuals deregistering from unemployment for at least four months. For caseworkers within public employment agencies, performance indicators are partly based on (registered) unemployment duration or status and partly on integration rates.

To test for differential effects of non-benefit recipients, Panel III in Table 3 interacts a dummy variable for "no receipt of benefits" with the treatment dummy "intensive in-house services". We find that non-benefit recipients spent fewer days in unemployment and withdrew earlier in both the control and treatment groups. Furthermore, in Agency 1, non-benefit recipients assigned to in-house services spent nearly two months less in unemployment, and the larger part of this effect stems from labor market withdrawals. No such effect is found, however, in Agency 2. Thus, the relative success of Agency 1 seems to be related to the fact that it had a much larger share of non-benefit recipients who spent fewer days in unemployment if assigned to internal teams. Although the effects of internal teams on days in employment and days spent in another status are not significant, they are larger for the latter. Whereas from the perspective of the employment agency, deregistration can be regarded as a desirable outcome, this is not necessarily the case from the perspective of the unemployed.

Furthermore, unemployed persons in East Germany seem to have been slightly older on average, and early retirement might be an interesting option for older unemployed persons. Thus, we interact a dummy variable for being 60 years of age and older with the treatment dummy. The 
results are displayed in Panel IV in Table 3. However, we do not find a significant effect of the interaction term, and treatment effects are similar to those in Panel I of Table $3{ }^{6}$

\subsection{Further analyses}

All in all, the relative success of public employment offices in delivering placement services seems to have arisen mainly in the short run. Nevertheless, even a shorter-term success warrants further investigation. In this section, drawing partly on qualitative research conducted by SOFI $(2010 a)^{7}$, we present several considerations that will shed some light on how and why this effect arises. We also present an empirical analysis of these topics. However, this research should be regarded as an exploratory rather than causal analysis.

\section{[Table 6 about here]}

First, incentives to use active labor market programs such as wage subsidies and training programs differ between both types of services (SOFI 2011: 108). The only restriction for internal teams was that they had to finance participation in such programs from the fixed budget available per unemployed person. In contrast, private providers only obtained the full performance payment component for individuals who were re-integrated into employment without the help of subsidies or other labor market programs. As a result, approximately 30 percent of the unemployed persons assigned to internal teams participated in short activation measures, such as application trainings or short measures providing skills, whereas much fewer control group members took part in such measures (Table 2). Panel I in Table 6 includes a dummy variable for participation in a further program that is interacted with the treatment dummy. The results indicate that those entering such further programs are a rather negative selection of unemployed persons. Although their results might have been even worse without participating in such a program, we think that it is safe to conclude that participation does not drive the positive short-term effects of internal services found in Section 3.2.

Furthermore, PES caseworkers might sanction unemployed persons by imposing a cut-off period from benefits if they do not comply with job search requirements. Private providers do not have the authority to impose such cut-off periods. Individuals assigned to internal teams did in fact experience more cut-off periods (Table 2), but the share of sanctioned individuals is rather low and differences are not significant. However, the share of imposed sanctions does not take

6 Because there were also differences in the gender and qualification composition of unemployed individuals across agencies, we further tested for heterogeneity effects by gender and with and without vocational training. We do not display the results because treatment effects were found to be rather similar to those given in Panel I of Table 3.

7 SOFI is short for „Soziologisches Forschungsinstitut Göttingen”. 
into account any potential ax ante effects of sanctions, i.e. a higher job search intensity or lower reservation wages of unemployed in anticipation of a potential cut-off period (Arni et al. 2012).

Second, the success of in-house placement services might arise because public providers face transaction costs that are absent in the case of in-house provision. Private providers have access to selected data collected by the PES. However, the in-house version of intensive placement services takes place immediately after randomization because unemployed persons only have to be transferred from the regular caseworkers to the new intensive-placement teams in the same public employment agency. In contrast, there is often a considerable time interval for those who are randomized into the control status, during which the depreciation of the unemployed person`s human capital continues, making it harder to provide him or her with suitable job offers. According to our data, the time gap until treatment at the private provider started for Agency 1 was 55 days on average, whereas it was 42 days on average for Agency 2 (Table 2). Such a time gap could, of course, be shortened, but transaction costs are difficult to avoid entirely. ${ }^{8}$

To derive an impression regarding whether the internal teams utilize this as a head start, Panel II in Table 6 interacts a dummy variable for early exits (during 60 days after assignment) with the treatment dummy. Again, the results are to be interpreted as correlations. We find that early exits are obviously a positive selection. Furthermore, treatment effects decrease, especially in Agency 1 (to a similar extent as when controlling for non-benefit receipts). This finding implies that the time gap might, in fact, play a role.

Third, our analysis considers all individuals assigned to the treatment or control groups. Twenty percent of individuals assigned to standard services, however, were non-compliers regarding assignment to a private provider. This observation may be caused by different reasons: First, dropout may be a result of selection, in which those individuals with the best labor market prospects drop out of unemployment in the mentioned time gap between randomization and the first appointment with the private provider. Second, being assigned to a private provider might have a "threat effect" that induces some individuals to de-register from unemployment. Third, caseworkers may - despite the provided instructions - have refused to enroll particular hard-toplace unemployed persons into the "Ganzil" program, in which case they should have received the regular placement services in the respective employment agency.

Panel III in Table 6 introduces a dummy variable for non-compliers in the estimates; the results must again be interpreted as correlations. The results confirm that those who do not attend are,

$8 \quad$ Furthermore, it should be noted that internal teams are specialized on the supply side of the labor market. However, they draw on the demand-side-oriented department of the public agency. In contrast, public providers are not served by this employer service (SOFI 2011: 108), so individual caseworkers in private agencies have to concern themselves with both the supply and demand sides or develop a division of labor of their own. 
in fact, a rather positive selection (thus, treatment effects increase considerably when controlling for non-compliance), which is in line with the first and second potential reasons mentioned. However, Table 2 also shows that for approximately two thirds of non-compliers, no indication of registration for "Ganzil" can be found in the data.

Fourth, the positive effects of internal teams might partly result from very small caseloads at the beginning of the project (see Figure A.1), which might have been reinforced by Hawthorne effects: Additional monitoring and extended team interaction might have induced team members to devote extra effort, particularly in the beginning of the project. To test for this possibility, we introduce a dummy variable that indicates assignment until the end of September 2009 and interact this with the treatment dummy. The results can be found in Panel IV of Table 3. Coefficients for both variables are insignificant and the main conclusions remain the same. Thus, we conclude that small caseloads and Hawthorne effects in the beginning of the project do not drive the observed results.

Fifth, contracting-out can only be expected to succeed if it takes place in a successfully implemented quasi-market. We have no information on whether ex ante competition really took place within Agencies 1 and 2. However, the fact that in both agencies, new companies won the right to supply placement services after contracts with previous providers had expired at the end of 2009 (SOFI 2010b: 32) at least suggests a competitive environment.

[Table 7 about here]

Behaghel et al. (2012) conclude from their study in France that fixed payment components with a 30 percent up-front payment - were sub-optimally high. The contract structures in both investigated German regions can be obtained from administrative files (MTH-P46); the resulting information on the contracts covering the vast majority of those assigned to the private providers is given in Table 7. In both agencies, the share of up-front payments was even higher than in the French study. The negotiated performance payment components and the negotiated re-employment rates were surprisingly low, particularly in Agency 2. Although contracts should cover fixed costs and reimbursements for participant costs (related to commuting and applications), this structure can obviously involve an agency problem.

Finally, there is the issue of efficiency in addition to effectiveness. A major argument in support of the implementation of quasi-markets is that they improve the cost-efficiency of placement services. Only if the higher re-employment probabilities induced by in-house placement services are cost-effective is there a strong case for intensive in-house placement services. If, in contrast, in-house placement services raise re-employment probabilities but are associated with higher costs, the case is not as clear. We present a basic cost-benefit assessment in the Appendix. Although results are strongly in favor of in-house services for Agency 1, the sign of the 
estimated net effects depends on the entry period analyzed for Agency 2. However, several caveats have to be taken into account; these are outlined in detail in the Appendix.

\section{$5 \quad$ Conclusions}

Our original question was as follows: Who should provide placement services, the public sector or private firms? We started out with some theoretical considerations about conditions for contracting-out to be an effective and efficient strategy. The creation of quasi-markets, where several potential providers of placement services compete with each through contract specifications in a bidding process, is considered to be the most important of these conditions. In-house production, however, can also have advantages, especially when high transaction costs are involved.

We then analyzed data from a randomized field experiment for hard-to-place unemployed persons in two German regions. Participants were randomly assigned to receive eight months of intensive placement services either by internal PES services or private providers. Our experimental design ensured the internal validity of the results; in other words, our estimates are not biased by any unobserved characteristics of the unemployed. Nonetheless, as is common with field experiments, we cannot claim the external validity of our results because we investigated only two agencies and two associated private providers of placement services. Furthermore, we focused on the direct effects of the experiment; indirect effects might occur, for instance, through a "crowding out" of unemployed individuals who were not hard-to-place but are not taken into account here.

Over an observation period of eighteen months, the experiment resulted in fewer days in unemployment and (to a lesser degree) more days in regular employment for unemployed persons subjected to in-house placement services. We therefore concluded that internal services were, in the short run (and during the treatment period of eight months), more effective than private services in reducing unemployment. This finding is in line with results from a similar experiment in France that was conducted by Behaghel et al. (2012). However, by the end of our observation period, differences in the shares of those in unemployment and employment more or less vanished. Thus, the (additional) effect of internal intensive services was not sustainable in the medium-run. Furthermore, only approximately one third of the difference in days in unemployment resulted from additional days of employment, and daily wages were (insignificantly) lower for those assigned to internal teams.

We subsequently presented a detailed discussion stating that a simple comparison of effectiveness might be misleading: Our results are most likely influenced by several important differ- 
ences that are only partially due to inherent aspects of in-house production and contracting-out. Such differences include friction in the transfer of unemployed individuals from public employment agencies to private providers. Furthermore, contract structures for providers might create relatively weak incentives for effective placement.

Taken together, our paper contributes one piece of evidence to the debate on the comparative effectiveness of the public and private provision of public services: We show that in a particular environment, the public provision of placement services can be as least as effective as contracting-out. More such pieces of evidence should be gathered to obtain deeper insights into the determinants of the relative success of these two modes of service provision.

Considering the target group of the experiment, our results demonstrate that the share of hardto-place unemployed individuals who found employment did not exceed 20 percent at any point in time, regardless of the public or private provision of intensive services. Whether a more effective approach to reintegrating hard-to-place unemployed persons into the labor market can be found remains a question for further research. 


\section{References}

Arni, P., Lalive, R, van Ours, J.C. (2012, online first), How Effective Are Unemployment Benefit Sanctions? Looking Beyond Unemployment Exit, Journal of Applied Econometrics, DOI: $10.1002 /$ jae.2289.

Bartlett, W., Le Grand, J. (1993), The theory of quasi-markets, in: Le Grand, J., Bartlett, W., (eds.) Quasi-markets and social policy. Macmillan Press, Basingstoke, UK, 13-34.

Behaghel, L., Crépon B., Gurgand, M. (2012), Private and Public Provision of Counseling to Job-Seekers: Evidence from a Large Controlled Experiment, IZA Discussion Paper 6518.

Bennmarker, H., Grönqvist, E., Öckert, B. (2013), Effects of outsourcing employment services: evidence from a randomized experiment, Journal of Public Economics 98, 68-84.

Bernhard, S., Wolff, J. (2008), Contracting out placement services in Germany: Is assignment to private providers effective for needy job-seekers?, IAB Discussion Paper 5/2008.

Blanco, G., Flores, C.A., Flores-Lagunes (2013, forthcoming), Bounds on Average and Quantile Wage Effects of Job Corps Training on Wages, Journal of Human Resources.

Boardman, A. E., Hewitt, E. S. (2004), Problems with contracting out government services: Lessons from orderly services at SCGH, Industrial and Corporate Change 13, 917-29.

Bruttel, O. (2005a), Contracting-out and Governance Mechanisms in the Public Employment Services, WZB Discussion Paper SP I 05-109.

Caliendo, M., Hujer, R. (2006), The microeconometric estimation of treatment effects - An overview, Allgemeines Statistisches Archiv 90, 197-212.

Caliendo, M., Kopeinig, S. (2008), Some practical guidance for the implementation of propensity score matching, Journal of Economic Surveys 22, 31-72.

Courty, P., Marschke, G. (2004), An Empirical Investigation of Gaming Responses to Performance Incentives, Journal of Labor Economics 22, 23-56.

Dehejia, R. H., Wahba, S. (2002), Propensity score matching methods for nonexperimental causal studies, The Review of Economics and Statistics 84, 151-161.

Domberger S., Jensen P. (1997), Contracting out by the public sector: theory, evidence, prospects, Oxford Review of Economic Policy 13, 67-78.

Duflo, E., Glennerster, R., Kremer, M., (2008), Using Randomization in Development Economics Research: A Toolkit, Handbook of Development Economics 4, 3896-3962.

Finn, D. (2007), Contracting Out Welfare to Work in the USA: Delivery Lessons, University of Portsmouth, Department for Work and Pensions Research Report 466.

Grout P. A., Stevens M. (2003), The Assessment: Financing and Managing Public Services, Oxford Review of Economic Policy 19, 215-234.

Hägglund, P. (2009), Experimental Evidence from Intensive Placement Efforts among Unemploymed in Sweden, IFAU Working Paper 2009/16.

Hainmueller, J., Hofmann, B., Krug, G., Wolf, K. (2011): Do lower caseloads improve the effectiveness of active labor market policies? New evidence from German employment offices. LASER discussion papers, 52

Heckman, J., Heinrich, C., Smith, J. (2002), The Performance of Performance Standards, Journal of Human Resources 38, 778-811. 
Kaltenborn, B., Wielange, N., Bothmer, A. Henkel, I. A. (2010), Zielsteuerung in der Arbeitsverwaltung - ein europäischer Vergleich, http://www.wipol.de/referenzen/projekte.htm\#bmas_zv .

Koning, P., Heinrich, C.J. (2010), Cream-Skimming, Parking and Other Intended and Unintended Effects of Performance-Based Contracting in Social Welfare Services, IZA Discussion Paper 4801

Konle-Seidl, Regina (2005): New delivery forms of employment services in Germany. A mixed public-private model? In: E. Sol \& M. Westerveld (Hrsg.), Contractualism in employment services. A new form of welfare state governance, (Studies in employment and social policy), The Hague u.a.: Kluwer Law International, S. 187-207Le Grand, J., Bartlett, W. (eds.) (1993), Quasi-markets and social policy. Macmillan Press, Basingstoke, UK.

Lee, D. (2009), Training Wages, and Sample Selection: Estimating Sharp Bounds on Treatment Effects, Review of Economic Studies 76, 1071-1102.

Mosley, H, Schütz H., Breyer, N. (2001), Management by Objectives in European Public Employment Services. Discussion Paper FSI01-203. Berlin: Social Science Research Centre (WZB). Pfeiffer, F., Winterhager, H. (2005), Vermittlungsgutscheine: Zwischenergebnisse der Begleitforschung 2004, Teil V, Kosten-Nutzen-Analyse, IAB Forschungsbericht 5/2005.

Pederson, J. M., Rosholm, M., Svarer, M. (2012), Experimental Evidence on the Effects of Early Meetings and Activation, IZA Discussion Paper 6970.

Rosenbaum, P. R., Rubin, D. B. (1983), The central role of the propensity score in observational studies for causal effects, Biometrika 70, 41-50.

Shleifer, A. (1998), State Versus Private Ownership, Journal of Economic Perspectives 12, 133 150.

SOFI (2010a), Evaluation/Implementationsanalyse zum Projekt „Interne ganzheitliche Unterstützung zur Integration im SGB III“ (PINGUIN), 1. Zwischenbericht, mimeo.

SOFI (2010b), Evaluation/Implementationsanalyse zum Projekt „Interne ganzheitliche Unterstützung zur Integration im SGB III“ (PINGUIN), 2. Zwischenbericht, mimeo.

SOFI (2011), Evaluation/Implementationsanalyse zum Projekt „Interne ganzheitliche Unterstützung zur Integration im SGB III“ (PINGUIN), Schlussbericht, mimeo.

Sol, E., Westerveld, M. (eds.) (2005), Contractualism in Employment Services. A New Form of Welfare State Governance, Den Hague: Kluwer Law International.

Stephan, G., Rässler, S., Schewe, T. (2006), Das TrEffeR-Projekt der Bundesagentur für Arbeit, Zeitschrift für ArbeitsmarktForschung 39, 447-465.

Struyven, L., Steurs, G. (2004), Quasi-market Reforms in Employment and Training Services: First Experiences and Evaluation Results, in: Descy, P, Tessaring, M. (eds.), Evaluation of Systems and Programs, Cedefop Reference Series 57.

Williamson, Oliver E. (1985), The Economic Institutions of Capitalism, New York: Free Press.

Winterhager, H. (2006a), Private job placement services: A microeconometric evaluation for Germany, ZEW Discussion Paper 06-026.

Winterhager, H. (2006b), Mikroökonometrische Analyse der direkten Effekte von Beauftragungen mit der gesamten Vermittlung, in: Kruppe, T. (eds.): Private Vermittlung als Unterstützung: Eine Evaluation von Vermittlungsgutscheinen und Beauftragungen Dritter, Beiträge zur Arbeitsmarkt- und Berufsforschung 301, Nürnberg. 
Winterhager, H. (2008), Öffentlich geförderte Beschäftigung von Arbeitslosen, ZEW Wirtschaftsanalysen 84, Baden Baden.

WZB, infas (2006), Evaluation der Maßnahmen zur Umsetzung der Vorschläge der HartzKommission, Arbeitspaket 1, Wirksamkeit der Instrumente, Modul 1a, Neuausrichtung der Vermittlungsprozesse, Bericht 2006, Berlin/Bonn.

Zhang, J., Rubin, D., Mealli, F. (2008), Evaluating the Effect of Job Training Programs on Wages through Principal Stratification, in: D. Milliment et al. (eds.), Advances in Econometrics XXL, Elsevier. 


\section{Tables and Figures}

Table 1 Means of characteristics $(0=$ no, $1=$ yes $)$ for those assigned to contracted-out services (C) and intensive in-house services (I) as well as differences in means (D)

\begin{tabular}{|c|c|c|c|c|c|c|}
\hline & \multicolumn{3}{|c|}{ Agency 1 (East) } & \multicolumn{3}{|c|}{ Agency 2 (West) } \\
\hline & $\mathrm{C}$ & I & $\mathrm{D}$ & $\mathrm{C}$ & I & $\mathrm{D}$ \\
\hline \multicolumn{7}{|l|}{ Individual characteristics } \\
\hline No receipt of benefits & 0.28 & 0.33 & 0.05 & 0.10 & 0.12 & 0.02 \\
\hline Women & 0.63 & 0.65 & 0.01 & 0.47 & 0.50 & 0.03 \\
\hline Married & 0.74 & 0.65 & $-0.08 * *$ & 0.70 & 0.68 & -0.02 \\
\hline Married women & 0.47 & 0.44 & -0.03 & 0.35 & 0.35 & 0.00 \\
\hline Searching for part-time work & 0.19 & 0.17 & -0.02 & 0.22 & 0.26 & 0.04 \\
\hline Foreign nationality & 0.06 & 0.04 & -0.01 & 0.24 & 0.24 & 0.00 \\
\hline Age $>40$ & 0.15 & 0.18 & 0.03 & 0.18 & 0.18 & 0.00 \\
\hline Age 40-49 & 0.13 & 0.15 & 0.02 & 0.15 & 0.20 & 0.06 \\
\hline Age $50-59$ & 0.48 & 0.48 & 0.00 & 0.48 & 0.41 & -0.07 \\
\hline Age 60 and older & 0.24 & 0.19 & -0.04 & 0.20 & 0.20 & 0.01 \\
\hline No secondary degree & 0.03 & 0.06 & 0.02 & 0.23 & 0.22 & -0.01 \\
\hline Secondary degree (Hauptschule) & 0.25 & 0.26 & 0.01 & 0.46 & 0.49 & 0.03 \\
\hline Secondary degree (Realschule) & 0.53 & 0.54 & 0.01 & 0.14 & 0.17 & 0.03 \\
\hline Secondary degree (Gymnasium) & 0.19 & 0.15 & -0.04 & 0.17 & 0.12 & -0.05 \\
\hline No vocational training & 0.07 & 0.08 & 0.02 & 0.25 & 0.21 & -0.04 \\
\hline Vocational training & 0.79 & 0.82 & 0.04 & 0.69 & 0.74 & 0.06 \\
\hline University degree & 0.14 & 0.09 & $-0.05 *$ & 0.06 & 0.04 & -0.02 \\
\hline \multicolumn{7}{|c|}{24 months before unemployment entry } \\
\hline Unemployment $<1$ month & 0.59 & 0.56 & -0.04 & 0.77 & 0.80 & 0.03 \\
\hline Unemployment 1-12 months & 0.26 & 0.32 & 0.06 & 0.20 & 0.18 & -0.02 \\
\hline Unemployment 13-24 months & 0.15 & 0.13 & -0.02 & 0.03 & 0.01 & -0.01 \\
\hline Employment $<1$ month & 0.29 & 0.33 & 0.04 & 0.15 & 0.19 & 0.04 \\
\hline Employment 1-12 months & 0.14 & 0.17 & 0.04 & 0.09 & 0.09 & 0.00 \\
\hline Employment 13-24 months & 0.57 & 0.50 & $-0.08 *$ & 0.76 & 0.72 & -0.04 \\
\hline Participation in program & 0.22 & 0.24 & 0.03 & 0.17 & 0.17 & -0.01 \\
\hline Period of sickness & 0.14 & 0.13 & -0.01 & 0.08 & 0.04 & -0.04 \\
\hline Sanction & 0.13 & 0.12 & -0.01 & 0.04 & 0.05 & 0.01 \\
\hline \multicolumn{7}{|c|}{ Month of assignment (or unemployment entry) } \\
\hline April & 0.04 & 0.01 & $-0.03 * *$ & & & \\
\hline May & 0.16 & 0.18 & 0.02 & & & \\
\hline June & 0.08 & 0.09 & 0.01 & 0.16 & 0.17 & 0.01 \\
\hline July & 0.07 & 0.09 & 0.02 & 0.13 & 0.13 & 0.00 \\
\hline August & 0.04 & 0.03 & -0.01 & 0.11 & 0.09 & -0.02 \\
\hline September & 0.07 & 0.05 & -0.02 & 0.11 & 0.12 & 0.00 \\
\hline October & 0.07 & 0.07 & 0.00 & 0.13 & 0.13 & 0.01 \\
\hline November & 0.14 & 0.15 & 0.01 & 0.11 & 0.10 & -0.01 \\
\hline December & 0.06 & 0.07 & 0.02 & 0.06 & 0.08 & 0.02 \\
\hline January & 0.20 & 0.19 & -0.01 & 0.13 & 0.10 & -0.03 \\
\hline February & 0.07 & 0.06 & -0.01 & 0.06 & 0.09 & 0.03 \\
\hline Number of observations & 414 & 412 & & 254 & 280 & \\
\hline MSB before matching & 7.1 & & & 6.7 & & \\
\hline MSB after matching ${ }^{\#}$ & 1.2 & & & 1.9 & & \\
\hline
\end{tabular}

*) $\alpha=0.05, * *) \alpha=0.01$.

\#) Radius matching with a caliper of 0.05 . 
Table 2 Participation in active labor market programs (in shares) during the observation period of 18 months for those assigned to contracted-out services (C) and intensive in-house services (I) as well as differences in means (D)

\begin{tabular}{lrccccc}
\hline & \multicolumn{3}{c}{ Agency 1 (East) } & \multicolumn{4}{c}{ Agency 2 (West) } \\
& C & I & D & C & I & D \\
\hline "Ganzil" taken up & 0.82 & 0.00 & $-0.82 * *$ & 0.78 & 0.00 & $-0.78^{* *}$ \\
"Ganzil" registration withdrawn & 0.07 & & & 0.07 & & \\
No "Ganzil" registration & 0.11 & & & 0.14 & & \\
Days until start of "Ganzil" & 55 & & & 42 & \\
\hline Self-employment program & 0.01 & 0.02 & 0.01 & 0.02 & 0.01 & -0.01 \\
Wage subsidy & 0.05 & 0.06 & 0.01 & 0.03 & 0.06 & 0.03 \\
Qualification program & 0.03 & 0.07 & $0.04 * *$ & 0.02 & 0.03 & 0.01 \\
Activation measure & 0.06 & 0.28 & $0.22 * *$ & 0.11 & 0.31 & $0.20 * *$ \\
Public employment & 0.00 & 0.01 & 0.00 & 0.00 & 0.00 & 0.00 \\
Other & 0.00 & 0.01 & 0.01 & 0.01 & 0.00 & -0.01 \\
\hline Cut-off period from benefits ${ }^{\#}$ & 0.01 & 0.03 & 0.02 & 0.05 & 0.08 & 0.03 \\
\hline Number of observations & 414 & 412 & & 254 & 280 & \\
\hline
\end{tabular}

*) $\alpha=0.05, * *) \alpha=0.01$.

\#)Within eight months after assignment; excluding sanctions due to severance payments.

Table 3 Treatment effects before and after matching, interacted with non-receipt of benefits and older age

\begin{tabular}{|c|c|c|c|c|c|c|c|}
\hline & & \multicolumn{3}{|c|}{ Agency 1 (East) } & \multicolumn{3}{|c|}{ Agency 2 (West) } \\
\hline & & $\begin{array}{l}\text { Unem- } \\
\text { ployed }\end{array}$ & Employed & Other & $\begin{array}{l}\text { Unem- } \\
\text { ployed }\end{array}$ & Employed & Other \\
\hline \multirow[t]{5}{*}{ I } & Before matching & & & & & & \\
\hline & Constant & $373 * *$ & $70 * *$ & $99 * *$ & $358 * *$ & $65 * *$ & $118 * *$ \\
\hline & Intensive in-house & $-70 * *$ & $24 *$ & $47 * *$ & $-37 *$ & 11 & 27 \\
\hline & Observations & 826 & & & 535 & & \\
\hline & $\mathrm{R} 2$ & 0.036 & 0.007 & 0.020 & 0.011 & 0.002 & 0.007 \\
\hline \multirow[t]{5}{*}{ II } & After matching & & & & & & \\
\hline & Constant & $365 * *$ & $71 * *$ & $106 * *$ & $350 * *$ & $67 * *$ & $124 * *$ \\
\hline & Intensive in-house & $-62 * *$ & $22 *$ & $41 * *$ & -27 & 9 & 19 \\
\hline & Observations & 818 & & & 554 & & \\
\hline & $\mathrm{R} 2$ & 0.028 & 0.006 & 0.015 & 0.006 & 0.001 & 0.003 \\
\hline & Constant & $394 * *$ & $73 * *$ & $73 * *$ & $367 * *$ & $69 * *$ & $105 * *$ \\
\hline & Non-benefit receipt & $-77 * *$ & -13 & $94 * *$ & $-85 *$ & -39 & $124 * *$ \\
\hline & Intensive in-house & $-47 * *$ & 17 & $31 *$ & -31 & 5 & 27 \\
\hline & Interaction term & $-56 *$ & 23 & 35 & -38 & 57 & -21 \\
\hline & Observations & 826 & & & 535 & & \\
\hline & $\mathrm{R} 2$ & 0.111 & 0.008 & 0.118 & 0.048 & 0.006 & 0.055 \\
\hline & Constant & $353 * *$ & $85 * *$ & $103 * *$ & $341 * *$ & $75 * *$ & $125 * *$ \\
\hline & Age 60 and older & $84 * *$ & $-67 * *$ & -19 & $85 * *$ & $-49 *$ & -37 \\
\hline & Intensive in-house & $-67 * *$ & $23 *$ & $46 * *$ & $-40 *$ & 16 & 26 \\
\hline & Interaction term & 5 & -9 & 2 & 19 & -23 & 3 \\
\hline & Observations & 826 & & & 535 & & \\
\hline & $\mathrm{R} 2$ & 0.073 & 0.046 & 0.022 & 0.057 & 0.035 & 0.014 \\
\hline
\end{tabular}

*) $\alpha=0.05, * *) \alpha=0.01$.

Note: OLS estimates; reference persons are those assigned to contracted-out services.

Left-hand side variables are accumulated days eighteen months after assignment took place. 
Table 4 Treatment effects on accumulated earnings in euro

\begin{tabular}{lrr}
\hline & Agency 1 (East) & Agency 2 West) \\
\hline Earnings & & \\
Constant & $2403 * *$ & $2836 * *$ \\
Intensive in-house & 595 & -20 \\
Observations & 826 & 535 \\
\hline R2 & 0.00 & 0.00 \\
\hline
\end{tabular}

Table 5 Treatment effects on first job after assignment for "always employed" persons

\begin{tabular}{lcccc}
\hline & \multicolumn{3}{c}{ Agency 1 (East) } & Agency 2 (West) \\
\cline { 2 - 5 } & All & Full time & All & Full time \\
\hline Contracted-out & 39 & 45 & 45 & 51 \\
Bounds on differential effect intensive & in-house services & & \\
I Individual level monotonicity & assumption & & & \\
$\quad$ Lower bound & $-10 * *$ & $-14 * *$ & -3 & -6 \\
Upper bound & 0 & -1 & -3 & -6 \\
II $\quad$ Adding weak monotonicity of mean potential outcomes & & \\
Lower bound & -5 & -7 & -3 & -6 \\
Upper bound & 0 & -1 & -3 & -6 \\
\hline III Observations and share & & & & \\
Observations & 307 & 214 & 173 & 125 \\
Share contracted-out & 0.34 & 0.22 & 0.33 & 0.24 \\
Share intensive in-house & 0.41 & 0.30 & 0.32 & 0.23 \\
\hline
\end{tabular}

*) $\alpha=0.05, * *) \alpha=0.01$.

Standard errors are obtained by bootstrapping with 90 percent of observations and 1000 repetitions. 
Table 6 Regression of outcome variables on treatment dummy and other variables

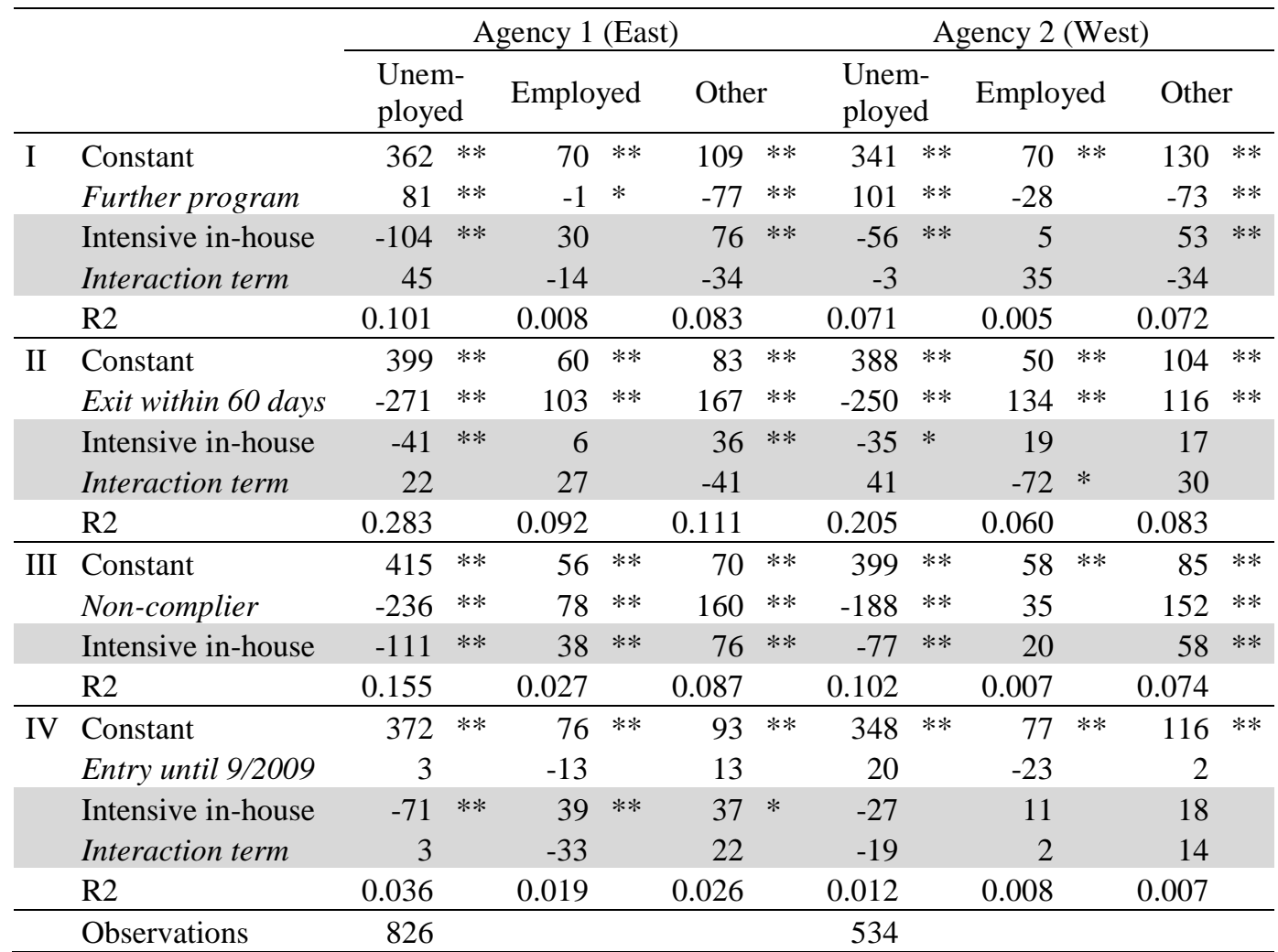

*) $\alpha=0.05, * *) \alpha=0.01$.

Note: OLS estimates (without matching); reference persons are those receiving unemployment benefits and assigned to contracted-out services.

Left-hand side variables are accumulated days eighteen months after assignment took place.

See Section 4.3 for an explanation of models I to IV.

Table 7 Contract structure for private providers in both agencies

\begin{tabular}{l|rr|r}
\hline & Agency 1 (East) & \multicolumn{2}{|c}{$\begin{array}{c}\text { Agency 2 } \\
\text { (West) }\end{array}$} \\
\hline Fixed payment component & 500 & 800 & 700 \\
1st performance payment component & 482 & 179 & 50 \\
2nd performance payment component & 482 & 179 & 50 \\
Malus component & 500 & 1000 & 500 \\
Risk component & 386 & 179 & 40 \\
Minimum re-employment rate & 22 & 22 & 15 \\
\hline Number of observations & 326 & 40 & 170 \\
\hline
\end{tabular}

Note: Information recovered from process-generated data (MTH-P46). 
Figure 1 Accumulated days in unemployment, employment or other status (withdrawal from the labor market) over time

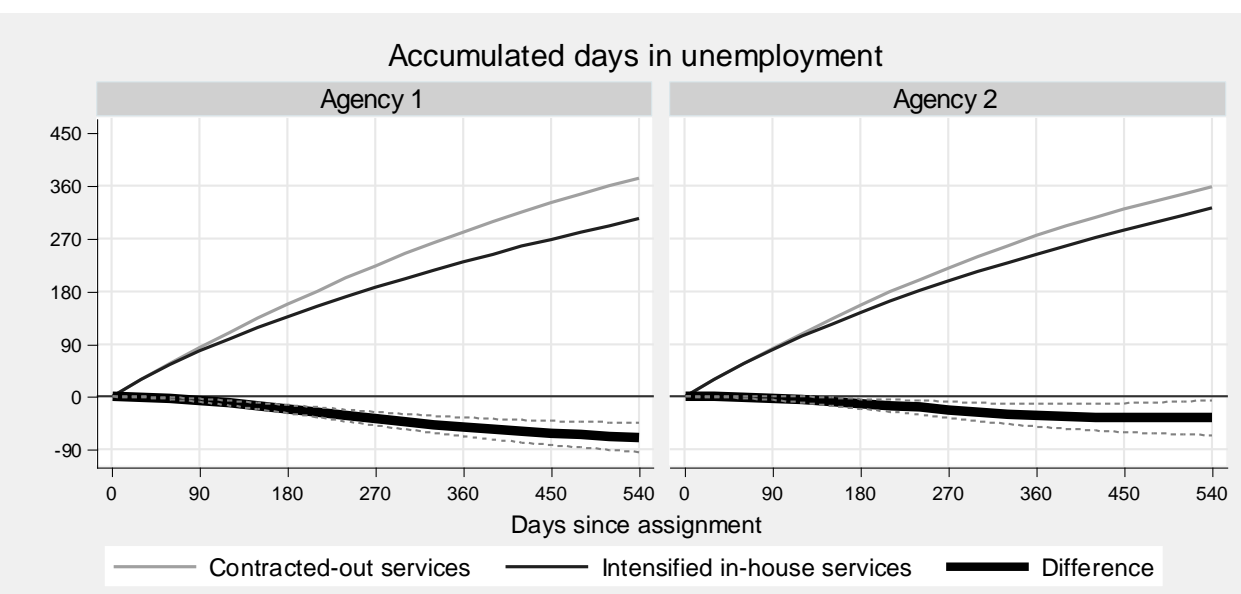

Comparison of means, Confidence intervals at 5-percent-level (dotted lines)

Accumulated days in employment

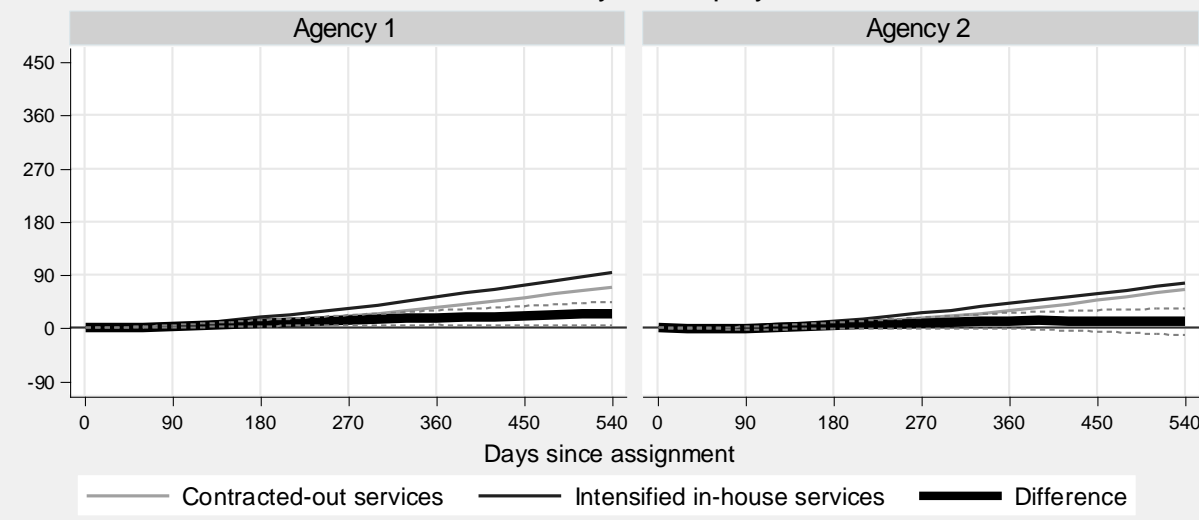

Comparison of means, Confidence intervals at 5-percent-level (dotted lines)

Accumulated days in other status

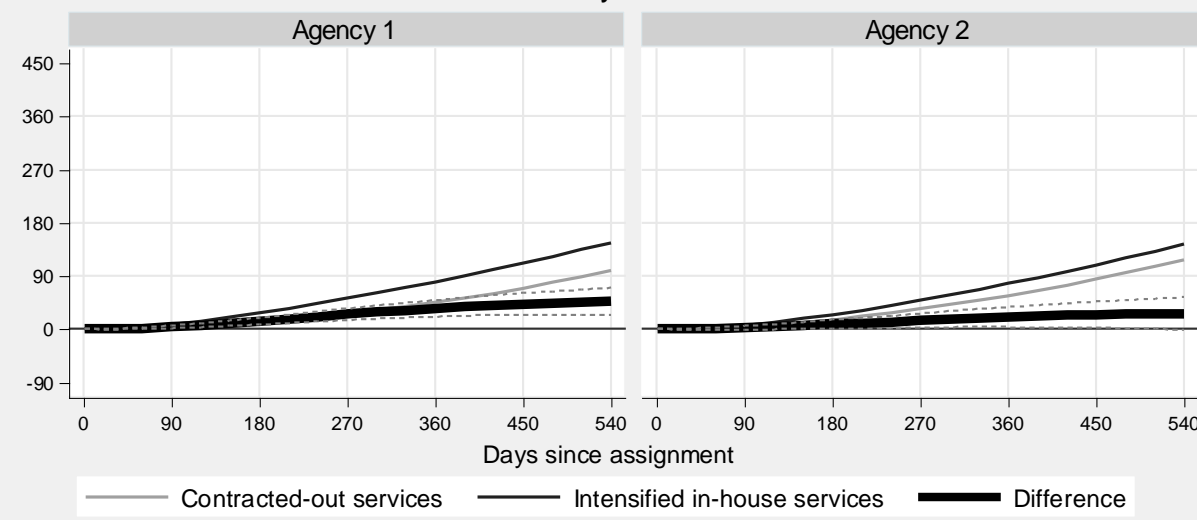

Comparison of means, Confidence intervals at 5-percent-level (dotted lines) 
Figure 2 Shares in unemployment, employment or other status (withdrawal from the labor market) over time

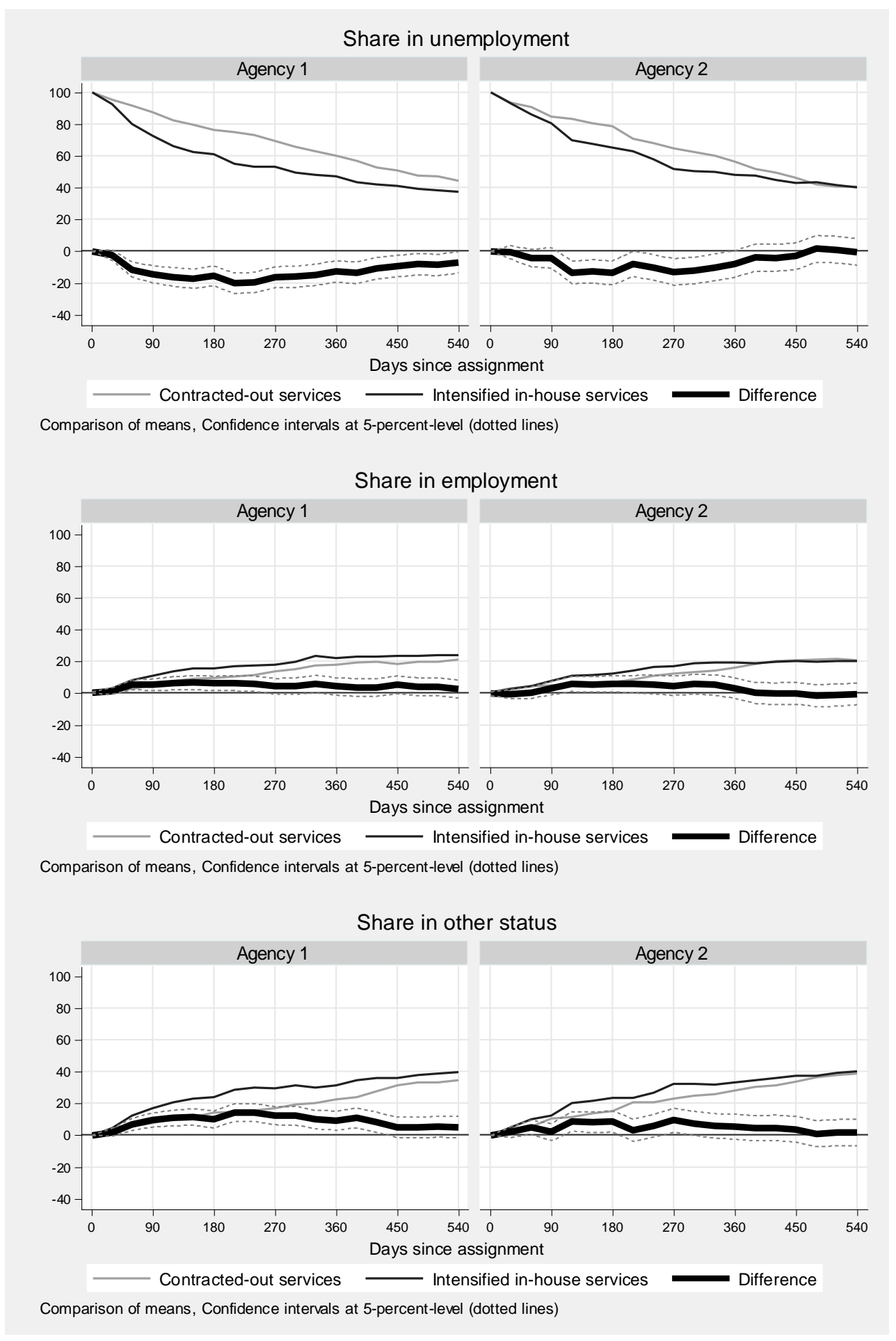


Figure A.1 Average caseloads of internal teams

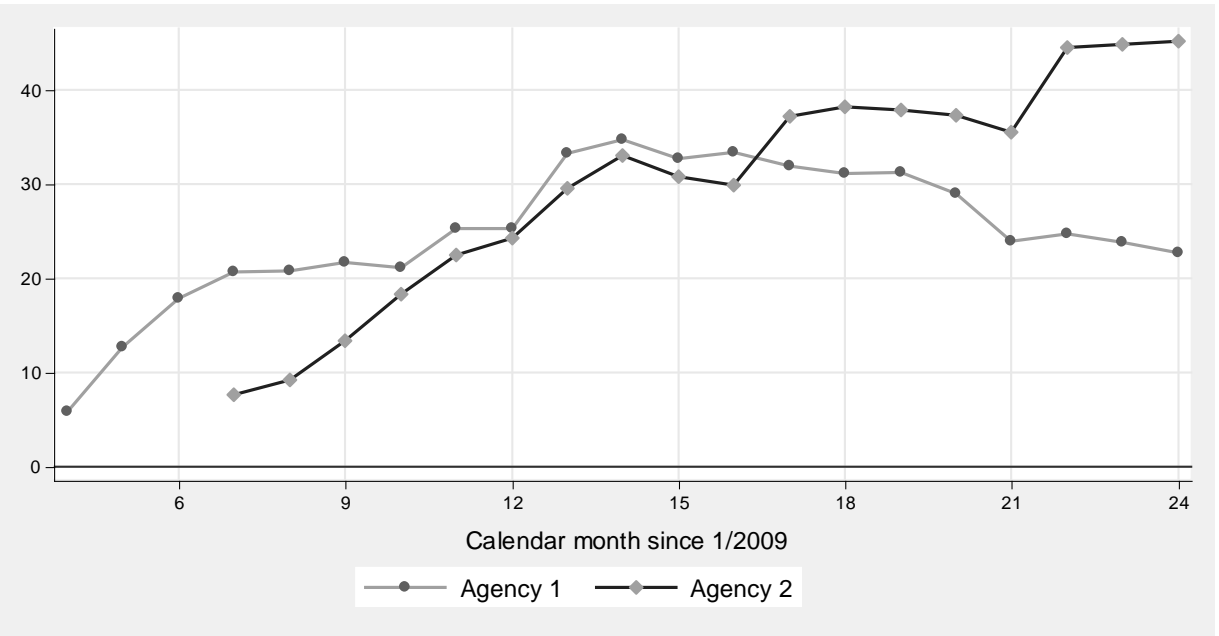

Note: Caseloads are computed by dividing monthly stocks, derived from team reports, by the number of caseworkers.

Figure A.2 Distribution of propensity scores for assignment into intensive in-house services
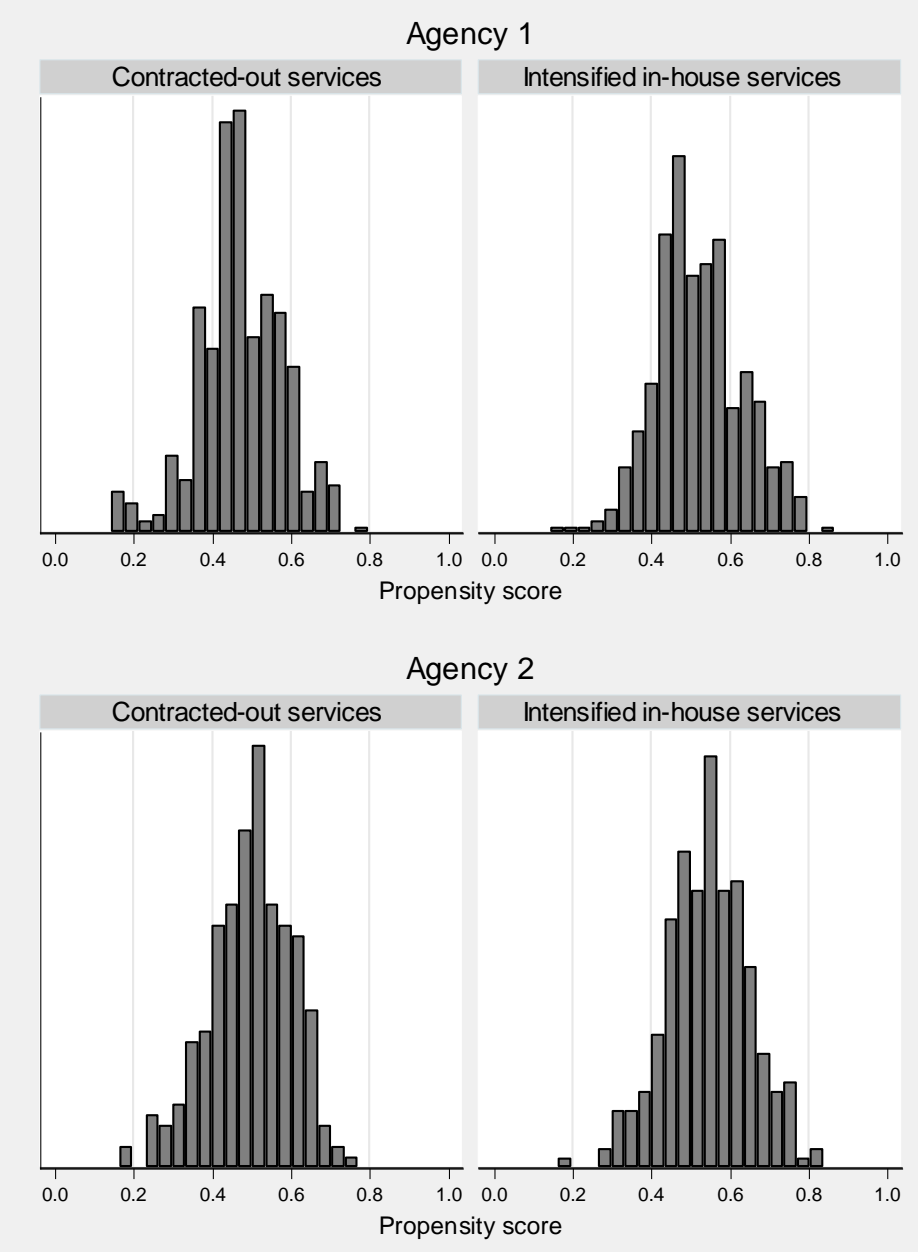

Note: Propensity scores are computed through a probit regression of the random assignment result on the variables described in Table 1. 


\section{Appendix: Basic cost-benefit assessment}

Table A1 Basic cost-benefit assessment (per capita) by entry period

\begin{tabular}{lrrrrrr}
\hline & \multicolumn{3}{c}{ Agency 1 (East) } & \multicolumn{2}{c}{ Agency 2 (West) } \\
\cline { 2 - 7 } & C* & I & C-I & C* & I & C-I \\
\hline Entries 4/2009 to 2/2010 & & & & & & \\
A) Costs of intensive services & 477 & 1113 & -636 & 528 & 1457 & -929 \\
B) Fixed budget expenditures & & 149 & -149 & & 123 & -123 \\
C) Unemployment benefits & 6228 & 5017 & 1211 & 8261 & 7324 & 937 \\
D) Unemployment insurance contributions & 67 & 84 & -17 & 79 & 79 & 1 \\
A + B + C - D = Fiscal costs for PES & 6638 & 6194 & $\mathbf{4 4 3}$ & 8710 & 8826 & $\mathbf{- 1 1 6}$ \\
\hline Observations & 414 & 412 & & 254 & 281 & \\
\hline Entries 9/2009 to 2/2010 & & & & & & \\
A) Costs of intensive services & 544 & 944 & -400 & 532 & 1047 & -515 \\
B) Fixed budget expenditures & & 149 & -149 & & 123 & -123 \\
C) Unemployment benefits & 6613 & 5232 & 1381 & 8388 & 7436 & 952 \\
D) Unemployment insurance contributions & 78 & 103 & -25 & 98 & 99 & -1 \\
A + B + C - D = Fiscal costs for PES & 7079 & 6221 & $\mathbf{8 5 8}$ & 8822 & 8508 & $\mathbf{3 1 4}$ \\
\hline Observations & 223 & 226 & & 123 & 139 & \\
\hline
\end{tabular}

$\mathrm{C}=$ Contracted-out services, $\mathrm{I}=$ Intensive in-house services.

*) Zero costs are assumed for non-compliers.

Note: Mean values.

From the viewpoint of the PES, Table A1 contains a very basic cost-benefit assessment at the individual level. We estimate direct fiscal net effects by comparing the estimated costs of intensive placement services, unemployment benefit expenditures and estimated contributions to unemployment insurance during our observation period of 1.5 years. This analysis is subject to several simplifications because not all relevant information is available. For instance, information on overhead expenses related to unemployment registration and the costs of standard services following the eight-month period of intensive placement services is missing, as are the costs arising from in-house services accessing the employment agency's employer-oriented placement services. Additionally, we have no information on the costs incurred by the centralized tendering process. Furthermore, the results would be biased upwards if relatively more individuals who had withdrawn from the labor market as a result of internal services were to renew their unemployment registrations and claim their residual amounts of unemployment insurance benefits after our observation period ended.

The average expected costs of contracted-out services are computed by combining the information from Table 6 with registered data on exits from unemployment to predict payments to private providers, assuming zero costs for non-compliers (row A). The average expected perperson costs of internal teams are computed using information on time spent in the program, assuming annual costs of 73,000 euro per caseworker and assigning costs on a daily basis, using monthly information on caseloads. This results in very high individual daily costs for the first 
months after the beginning of the project, when caseloads were still being built up (Figure A.1). Thus, we present additional estimates for assignments taking place since 9/2009.

We add monitoring information on expenditures for the fixed budget (row B), but disregard costs for further labor market programs that took place after the period of intensive placement services (because cost information is not available on these). Average costs for unemployment benefits were obtained by multiplying days with unemployment benefits (zero for non-benefit recipients) with the individual benefit rate during each spell of unemployment (row D). We compute additional income for unemployment insurance by multiplying earnings during the observation period by the current contribution rate (row E).

We find that the costs of the internal service were two to three times the average costs of contracting-out, assuming zero costs for non-compliers. This is compensated by lower unemployment benefit payments (as long as we do not find individuals spending more days on social security). On average, for our entire sample, this very basic fiscal cost-benefit analysis finds an advantage of nearly around 440 euro per capita for internal services in Agency 1 but a disadvantage of approximately 120 euro per capita in Agency 2. If we restrict the analysis to entries since 9/2010, the results are somewhat more in favor of in-house services (advantages of approximately 560 and 310 euro, per capita respectively, for Agencies 1 and 2). 